\title{
IOS ADOPTION IN DENMARK
}

\author{
Explanatory aspects of organizational, environmental and \\ technological attributes
}

Helle Zinner Henriksen

Department of Informatics, Copenhagen Business School, Denmark

\begin{abstract}
Adoption and especially non-adoption of technologies, which are believed to yield operational and strategic benefits for businesses, are not always easy to comprehend. In this study we have surveyed businesses in the Danish steel and machinery industry to get an insight into what motivates or de-motivates adoption of IOS exemplified by EDI. The reason for choosing this particular industry is that it has been a target for massive information campaigns concerning the potential benefits of EDI adoption. In accordance with the Tornatzky \& Fleischer (1990) model for organizational adoption fifteen opinion data items related to organizational, environmental, and technological attributes were operationalized and analyzed. The study suggests that environmental and organizational attributes rather than technological attributes are the main determining forces for adoption of EDI.
\end{abstract}

Key words: IOS adoption, quantitative measurement, impacts of organizational attributes, environmental attributes, and technological attributes.

\section{INTRODUCTION}

Why are some organizations adopting a technological innovation that is announced to yield both operational and strategic benefits while others hesitate, or decide not to adopt for the time being? This question is highly relevant especially in the case of interorganizational information systems (IOS) exemplified by EDI (electronic data interchange), due to the great attention this particular technology had received throughout the 1990s from academia, practitioners, and governments all over the world. Surprisingly few Danish organizations have adopted EDI. If their technical capabilities and their high degree of computerization are considered, then the 
organizations' reluctance to adopt EDI appears to be even more irrational and incomprehensible. The phenomenon of organizations not adopting IT regardless of their claimed opportunities to do so is well known (Harrison et al., 1997). What is missing so far are factors explaining the reason for this situation.

Small companies dominate the Danish business sectors. About two third of the approximately 50,000 companies within the industrial sector have less than ten employees. National and international industry and trade associations have created a number of awareness campaigns and have focused on creating beneficial conditions for the SMEs (small and medium sized enterprises) in order to get them to adopt IT, especially IOS such as EDI. The aim is to help the companies reduce or eliminate work routines and to support them in a market characterized by increased competition. The technological development has led to an increase in quality and functionality and a decrease in cost of hardware and software (Harrison et al., 1997). The traditional technological barriers for organizational adoption of IOS such as EDI might therefore not play the same dominant role as it did earlier. This new situation makes it highly relevant to examine explanatory factors for EDI adoption among SMEs, which traditionally have less resources allocated to IS compared to larger companies (Lai \& Guynes, 1997).

In order to find an explanation for the puzzle of the limited EDI adoption and diffusion among Danish businesses a survey was conducted. The survey addressed SMEs in the Danish steel and machinery industry. The reason for choosing this sector was that business associations had targeted information campaigns towards this sector prior to the data collection and therefore the survey aimed at analyzing the patent priorities of the responders with respect to adoption of EDI.

The remainder of this paper is organized as follows. The next section conceptualizes adoption. The following section presents the applied research method. Thereafter, the research model is outlined. This section is followed by a description of how the research model is operationalized. The next section deals with the statistical analysis and the results. The penultimate section discusses the results from the statistical analysis. The paper ends with some concluding remarks concerning the implications of the results.

\section{THEORY: ADOPTION OF INNOVATIONS}

There are two dominant views on adoption. Adoption can be seen as having or not having an innovation (Tornatzky \& Fleischer, 1990), or it can be seen as using the innovation versus not having it (Rogers, 1995). Adoption is according to Rogers “... a decision to make full use of an 
innovation as the best course of action available and rejection is a decision not to adopt an innovation." According to this view the line between adoption and use of the innovation is non-existing. Rogers argues, that the adoption process is a process through which a decision-making unit passes. The steps are: gaining knowledge of an innovation, forming an attitude toward the innovation, making a decision to adopt or reject, implementing the new idea, and finally to confirmation of the adoption decision. In this course of events the adoption process is considered to be merely a mental exercise until implementation takes place.

In this paper the core understanding of the term adoption is "having versus not having" (Tornatzky \& Fleischer, 1990) rather than "not having versus using" (Rogers, 1995). Consequently, measures on effects of the adoption of the innovation are not performed. The important point in this study is that some dividing line is crossed where the participants decide to invest resources necessary to accommodate the effort to change (Kwon \& Zmud, 1987).

\section{RESEARCH METHOD}

The method selected for the collection of survey data was a postal questionnaire. During Spring of 2000 the questionnaires were mailed to the managerial unit in the organizations involved. The questionnaire was mailed by two industry and trade associations and the cover letter carried the letterhead of the respective association. It was expected that data collection using this procedure would be perceived as more authoritative than usual questionnaires received in organizations, and that this procedure accordingly would result in a better response-rate.

The questionnaire was sent to the management of 917 manufactures and wholesalers in the steel and machinery sector in Denmark. It is part of the internal policy of the two involved associations not to burden their members with too much mail. Therefore, a second mailing was not allowed. A total of 252 responses were received, out of which 247 could be included in the analysis.

The 247 returned valid questionnaires equal a response rate of 27.4 percent. The response rate approximately equals similar other studies related to the adoption of IOS. For example 25.7 percent (Chau, 2001) and 27 percent (Masters et al., 1992). Some other studies focusing on both adopters and non-adopters of information systems have generally reached response rates that are somewhat lower. For example 18.4 percent (Lai \& Guynes 1997) and 19 percent (Crum et al., 1996). Compared to other studies, which have included both adopters and non-adopters, the response rate of the 
present study is satisfactorily, especially when the collection procedure with only a single mailing is taken into consideration.

A number of similar studies have applied various multivariate parametric data analysis methods. These methods include factor analytic techniques such as principal component analysis, which has been applied by Chau (2001) and Premkumar and Ramamurthy (1995) and factor analysis, which has been applied by Chau and Tam (1997) and Grover (1993). The strengths of factor analytic techniques are their usefulness for summarizing items and data reduction, thereby possibly uncovering "latent" dimensions that hopefully describe data in a smaller number of concepts compared to the original variables.

Both the principal component method and the method of exploratory factor analysis are based on a matrix of Pearson correlation coefficients and data should therefore satisfy the assumptions for these statistical methods (Hatcher \& Stepanski, 1994). Therefore, all relevant Likert-scale items from the survey of the steel and machinery industry were tested for normality. The results of the Shapiro-Wilks test showed p-values ranging from 0.0979 to < 0.0001 . It is possible that some transformations of data could have overcome this non-normal distribution of data. However, it can be argued that Likertscales are merely manifestations of ordered categories (Siegel \& Castellan, 1988) and therefore the requirement of at least an interval-scale for the Pearson correlation coefficient is not met. Based on the above-mentioned considerations and findings it was found prudent to focus on non-parametric methods of analysis.

The main objective of the statistical analysis is to uncover the patent priorities of the responders with respect to adoption of EDI. In this respect patent priority refers to the manifest, face value expressions of the responders. This approach is different from searching for latent factors or structures as normally done in factor analytic techniques.

Firstly, Cronbach coefficient alpha was estimated. Cronbach coefficient alpha is used as a measure of reliability in relation to the operationalization of the constructs from the Tornatzky and Fleischer model (1990). The objective of these reliability estimations is to investigate the strength of the three groupings of items related to the organizational context, the environmental context, and the technological context given adoption level.

The next two steps in the quantitative analysis of data are exploratory searches for items related to the three adoption levels. Two steps are used to identify the factors motivating or de-motivating adoption of EDI. Fischer's Exact two-sided test on two-by-two tables is used to identify those items that are strongly related to each one of the three levels of adoption. Fischer's Exact test is chosen because many cell-counts in the two-by-two tables are rather small. Data was then analyzed by applying graphical models using the 
software application DIGRAM. This is done, because it is found prudent to analyze the relationships between all the items taken together and the respective levels of adoption. Contrary to the two-way analysis using Fischer's Exact test the analysis performed in DIGRAM is a multivariate analysis technique. One of the strengths of graphical modeling is the ability to analyze causal structures. In this particular case the causal structure between the items and a given level of adoption.

Logistic regression analysis is the final step in the search for patent priorities. The independent, explanatory items for logistic regression analysis are the items that were identified either by the two-way tables using Fischer's Exact tests and/ or through the exploratory analysis performed in DIGRAM.

Similar to other adoption studies (Moore \& Benbasat, 1991) multi-item indicators were used for the opinion data items concerning the motivation for adoption. Seven-point Likert scales ranging from "fully agree" to "strongly disagree" were applied. Due to the limited number of responders it was necessary to reduce the seven-point scales to binary scales. These binary scales were constructed to reflect agreement and disagreement with the adoption item in question. The Likert scale points 1 to 3 defined agreement whereas the points 4 to 7 defined disagreement. Point four on the sevenpoint Likert scale in question is considered to indicate a neutral response. It was decided to include the neutral response with points 5 to 7 , because a response value of 1 to 3 reflects definite agreement with the item, whereas response values 4 to 7 indicate neutral to non-agreement.

In order to analyze possible differences between those responders that had adopted EDI, those who were in the process of adopting EDI, and those that found it irrelevant to consider EDI adoption for the time being, the responders were divided into three sub-groups: adopters, planners, and nonadopters. Adopters and planners were asked the very same questions. For non-adopters all questions were phrased negatively. ${ }^{1}$ In the subsequent analysis of data all opinion data item values were "reversed" for nonadopters.

Generally, one of the first tasks when conducting questionnaire research is to assess the reliability of the constructs. If the scales are not reliable there is no point in performing additional analyses. An analysis of Cronbach's coefficient alphas was performed based on the operationalization of the three constructs: Organizational context, environmental context, and technological context given adoption status.

${ }^{1}$ An example of negative phrasing is: "None of our business partners are using EDI" versus the positive phrasing for adopters: "All our business partners are using EDI." 
Table 1. Cronbach's coefficient alpha for the three constructs

\begin{tabular}{lccc}
\hline Construct & Adopters & Planners & Non-adopters \\
\hline Organizational context & 0.76 & 0.72 & 0.82 \\
Environmental context & 0.70 & 0.74 & 0.82 \\
Technological context & 0.52 & 0.34 & 0.49 \\
\hline
\end{tabular}

Generally, the lower acceptable limit for summed scales is considered to be 0.70 (Nunnally, 1978). The constructs for organizational context and environmental context are of an acceptable reliability level independent of adoption status. On the other hand, the operationalization of technological context is below the generally acceptable reliability level independent of adoption status.

\section{RESEARCH MODEL}

Tornatzky and Fleischer (1990) suggested that three explanatory contexts influence the process by which innovations are adopted in organizations. These three contexts are: the organizational context, the environmental context, and the technological context.

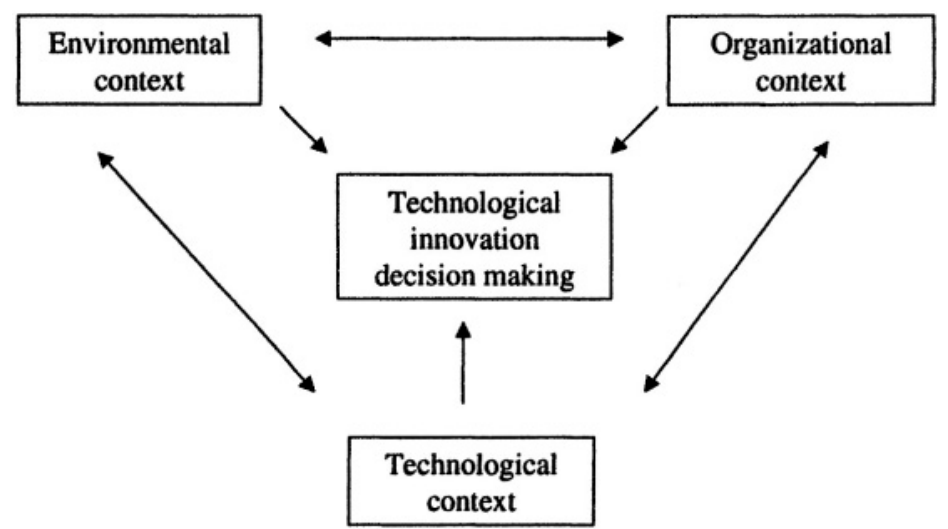

Figure 1. The Tornatzky and Fleischer (1990) model for adoption

This overall categorization in Figure 1 were operationalized in the further study of the Danish steel and machinery industry.

\section{OPERATIONALIZATION OF THE RESEARCH MODEL}

Fifteen propositions are constructed based on the three categories presented in Figure 1. The fifteen propositions are based on secondary 
innovation attributes and the statistical analysis is therefore based on qualitative statements from informants.

\subsection{Nature of the opinion data items}

The operationalized adoption-decision variables in relation to EDI are mainly related to secondary innovation attributes (Downs \& Mohr, 1976). Downs and Mohr distinguished between primary and secondary innovation attributes. Primary attributes are viewed as inherent in the innovation and invariant across settings and organizations e.g. company size, which can be measured fairly objectively. Secondary attributes are defined as perceptually based on subjective characteristics for example complexity and relative advantage. The perception of secondary attributes is assumed to be influenced by characteristics of both the particular setting as well as actors involved in adoption of a particular innovation. It is therefore acknowledged that the measures applied in the survey are subjective in the sense that they are perceived and interpreted in the mind of the responder.

The major distinction between the operationalization of the organizational context and the environmental context is whether the opinion data item is within or beyond the control of the organization. Control should in this context be understood as the organizations' (perceived) capability of influencing the adoption process and the possible outcome of adoption. That is for example the case for issues related to improvement of work environment or the organizations' capability of calculating the potential benefits of adoption. The opinion data items related to the environmental context are on the other hand facilitated or constrained by interaction with business partners. Examples include different degrees of power exerted on the organization and competitive forces.

\section{$5.2 \quad$ The organizational context}

The organizational context comprises attributes related to the organization. Tornatzky and Fleischer suggest that the organization provides a rich source of structures and processes that constrain or facilitate the adoption of innovations. These structures and processes can be formal or informal.

Generally profitability has been found to be a motivator for adoption of IS (Attewell, 1992). One rationale for adopting EDI is an expectation of increased efficiency due to improvement of intraorganizational and interorganizational routines (Timmers, 2000). Among the operational performance themes identified in the IS literature were: General performance improvements (Clark \& Stoddard, 1996), accurate exchange of 
business information (Srinivasan et al., 1994), and benefits related to integration of EDI (Massetti \& Zmud, 1996; Premkumar et al., 1994; Truman, 2000). Direct savings are rarely reported in EDI studies (Cox \& Ghoneim 1996; O'Callaghan \& Turner, 1995). Indirect savings are on the other hand often explored. These savings can be related to reduction in the workforce due to less re-keying and a decreased need for manual storing of documents, lower inventory costs, and shortened duration of transactions (O'Callaghan \& Turner, 1995). The following proposition was formulated in order to examine whether the possible savings related to EDI have influenced a company's motivation for EDI adoption:

Proposition 01: Prospects of future savings motivate EDI adoption.

Tornatzky and Fleischer (1990) focus on human resources in relation to the organizational context. IS studies have included issues such as adequate education (Kurnia \& Johnston, 2000) and employees' IS knowledge (Thong, 1999). The EDI literature has to a limited extent focused on issues related to work environment and human resources. Swatman and Swatman (1992) point out that adoption of EDI may lead to organizational restructuring involving staff retraining due to changing work functions. Especially training of all relevant employees has been found to be one of the major determinants for SMEs gaining benefits from EDI adoption (O'Callaghan \& Turner 1995; Raymond \& Bergeron, 1996). In order to investigate the importance of work environment and human resources in relation to motivation for EDI adoption three propositions were formulated.

Proposition $\mathrm{O} 2$ is related to, whether or not it is perceived that adoption of EDI will create better work conditions for employees leading to more independent job functions for employees. O'Callaghan and Turner (1995) characterized this situation as "Freeing professionals from administrative tasks."

Proposition 02: The notion that EDI will create a better work environment is a motivator for EDI adoption.

Proposition $\mathrm{O} 3$ is related to whether or not adoption of EDI will lead to training and education of employees. Re-training due to changes in staff functions as described by Swatman and Swatman (1992) was the underlying assumption for this proposition.

Proposition 03: The notion that EDI will benefit the development and utilization of human resources is a motivator for EDI adoption.

The theoretical inspiration for Proposition O4 can be found in the oftenclaimed benefit of EDI related to the elimination of redundant re-keying and elimination of manual reconciliation (Arunachalam, 1995; O'Callaghan \& Turner 1995). One improvement of the work environment is seen in relation to elimination of trivial work and routines. 
Proposition 04: The notion that EDI will eliminate trivial work is a motivator for EDI adoption.

Most EDI studies have focused on commodities and standardized products such as aircraft parts (Choudhury et al., 1998), hospital supplies (Steinfield et al., 1995), and office supplies (Jelassi \& Figon, 1994). Research has especially shown a high level of implementation of EDI in the automotive industry (Tuunainen, 1998) and in the grocery sector (Andersen et al., 2000). Commodities and standardized products characterize both these sectors. Even though EDI is useful for exchanging business information regardless of whether the item is a commodity or something highly specific, the EDI literature and practice have so far mainly concentrated on commodities. To investigate whether or not the type of business activities influences the motivation for EDI adoption the following proposition was formulated:

Proposition 05: The decision-makers' awareness that the company's business activities are well suited for EDI is a motivator for EDI adoption.

One study (Iacovou et al., 1995) directly referred to organizational readiness for EDI. The study related organizational readiness to the level of financial and technological resources. Lai and Guynes (1997) referred to employee's positive attitude to organizational change. One aspect, which has been seen as a parameter for organizational readiness for EDI adoption, is related to whether the adopters are EDI initiators or followers (Swatman \& Swatman 1992). Companies that are persuaded or directly forced to adopt EDI are not well prepared for EDI and as a consequence might not immediately reap the full benefits of EDI - if ever. In order to investigate the importance of organizational readiness proposition $\mathrm{O6}$ was formulated:

Proposition O6: The notion that companies consider themselves to be well prepared for EDI are more likely to adopt EDI.

\subsection{The environmental context}

The environmental context is the arena in which a firm conducts its business. Included in this context are the organization's competitors, its access to resources supplied by others, and its dealings with government. AH these elements can influence the way an organization views the need for adoption of innovations. Tornatzky and Fleischer suggest that two aspects of the external environment are key determinants of innovative activity: The competitive characteristics of its industry and the existence of a relevant technology support infrastructure.

Recalling that the environmental context is the arena in which the organization conducts its business (Tornatzky \& Fleischer, 1990) the improvement of strategic performance is an important issue in relation to 
IOS adoption. Three IS studies, which have included the environmental context in their survey instrument, have focused on competition (Kurnia \& Johnston, 2000; Thong, 1999; Grover, 1993). A number of studies have found that adoption of EDI could lead to competitive advantages such as improved competitiveness (Chatfield \& Bjorn-Andersen, 1997), new business opportunities (Jelassi \& Figon, 1994), and changes in interfirm processes and politics (Lee et al., 1999). To investigate whether competitiveness influences the motivation for EDI adoption Proposition E1 was formulated.

Proposition E1 is directly related to possible improved competitiveness due to EDI adoption. The proposition rests on some of the "traditional" assumptions related to EDI. These include a possible increase in the company's competitiveness due to e.g. improved customer service, shorter lead times, and more timely information about transaction status (Arunachalam 1995; O'Callaghan \& Turner 1995; Dearing, 1990).

Proposition E1: The prospect of improving the company's competitiveness motivates EDI adoption.

Proposition E2 is related to the strategic alliances between business partners for the purpose of maintaining a competitive edge (Chau \& Tam 1997).

Proposition E2: The prospect of increasing the company's market share is a motivator for EDI adoption.

The items related to interorganizational forces contain issues related to power and pressure. This perspective when seen as a driver for IS adoption refers to the obligation of a firm to adopt an innovation in order to keep a customer or supplier content (Hart \& Saunders, 1998). Hart and Saunders (1998) explored the different ways of exerting power in relation to business partners. They distinguished between persuasive and coercive power. Iacovou et al. (1995) distinguished between competitive pressures and imposition by trading partners. Bergeron and Raymond (1992) included the benefits from strategic repositioning of the firm due to implementation of EDI in their survey. Pressure related to imposition of business partners (Iacovou et al., 1995) was operationalized in Proposition E3 which is related to the knowledge that EDI is being used amongst business partners.

Proposition E3: The knowledge that several business partners already use EDI is a motivator for EDI adoption.

Proposition E4 is related to the situation where the company is subject to persuasive power (Hart \& Saunders, 1998). The company is not directly forced to adopt EDI but business partners may take steps such as informing about EDI benefits and offering assistance in relation to the adoption and implementation process. 
Proposition E4: The fact that EDI has been recommended by others is a motivator for EDI adoption.

Proposition E5 is related to direct pressure from business partners. Pressure can take different dimensions ranging from promises to threats (Iacovou et al., 1995). Promises include rewards such as rebates due to EDI usage and threats include negative sanctions such as suspension of the partnership.

Proposition E5: The fact that the company is put under pressure to use EDI is a motivator for adoption of EDI.

\subsection{The technological context}

The technological context comprises both the internal and external technologies relevant for the firm. It includes current practices and equipment internal to the firm as well as the pool of available technologies external to the firm. Decisions to adopt a technology depend on what is available, as well as how the available technology fits the firm's current technology. Tornatzky and Fleischer call attention to the fact that not all innovations are relevant to all industries.

One inevitable problem in relation to an examination of the three contexts in one questionnaire is the wide scope of the three contexts. It is difficult or nearly impossible to find a single person in an organization that can provide answers to all questions related to the organization. In order to avoid a situation where the manager was unable to answer issues related to the technological context, the questions were formulated in general terms focusing on the managerial aspects of technology.

Other things being equal, the more costly an innovation is, the less likely it is to be adopted, but once it is adopted and adapted, the large investment may strongly motivate implementation of the innovation (Cooper \& Zmud, 1990). As for the cost of technical solutions, it can be seen as the direct price of purchase or in relation to both direct costs and expenses resulting from education and training of employees (Raymond \& Bergeron 1996).

Proposition T1 is related to how managers perceive the importance of the technical level of EDI. Instead of specifically investigating issues related to standards, means for transportation, or prospect of integration this opinion data item was kept in very general terms.

Proposition T1: A satisfactory technical level of IT solutions is a motivator for EDI adoption.

Proposition T2 is directly related to price. A theoretical reference to T2 is the relative advantage of EDI adoption (Rogers, 1995) or cost-benefit considerations. 
Proposition T2: A satisfactory price level of IT solutions is a motivator for EDI adoption.

None of the reviewed studies concerning EDI or adoption of IOS specifically included issues related to the threat of "technological marginalization" due to reluctance to adopt a technological innovation. The reviews were rich in examples of "economic marginalization" in the sense that non-adoption for example could lead to weakened competitive advantages. The adoption and diffusion theory is rich in examples related to the issue of technological marginalization. The S-curve often used to explain diffusion of technology (Attewell, 1992) conceptualizes the technological marginalization in the sense that it postulates that adopters can be divided into five groups: Innovators, early adopters, early majority, late majority, and laggards (Rogers, 1995). The last two opinion data items related to the technological context can from a theoretical point of view be related to the issue of managerial fashion innovation (Abrahamson, 1996). The fads and fashion perspective is related to the situation where managers actively search for innovations that can upgrade their businesses technologically (Newell et al., 2000).

The first perspective is related to the situation where the potential adopter is in a neutral position towards the innovation per se. However, mere knowledge that not having the innovation might exclude the company from being up-front might serve as a motivator for adoption. The threat of being a laggard (Rogers, 1995) with respect to adoption was formulated in Proposition T3.

Proposition T3: A feeling of being left behind with respect to EDI is a motivator for EDI adoption.

Proposition T4 is directly related to the fads and fashion phenomenon presented by Abrahamson (1996). It should be noted that though researchers do not perceive EDI as new and interesting this might not be the case for practitioners. Innovation is a relative term, which is conditioned by the perception of the potential adopter (Zaltman et al., 1973).

Proposition T4: The notion that EDI is new and interesting is a motivator for EDI adoption.

\section{STATISTICAL ANALYSIS AND RESULTS}

Fischer's Exact tests were performed on all the original opinion data items transformed to binary variables related to the three adoption levels: Adopters, planners, and non-adopters.

Based on the results from Fischer's Exact test it was found that six items are strongly related to adoption. Four items were found to be of importance 
for planners, and nine items were of importance for non-adopters. The Fischer's Exact tests are based on analysis of two-by-two tables. These relationships are all two-dimensional. However, to uncover influences from multi-way dimensions and to identify possible causal structures these same opinion data items were included in a multivariate analysis based on graphical models. This was done, because it was found relevant to analyze the relationships between all items taken together versus the three levels of adoption.

The exploratory multivariate analysis suggests that four opinion data items that have a causal relationship with adoption. For planners there were causal relationships with three opinion data items. Finally, for non-adopters five causal relationships were found.

Table 2. Opinion data items identified for inclusion in binary logistic regression

\begin{tabular}{|l|l|l|l|l|l|l|l|l|l|l|}
\hline \multirow{2}{*}{$\begin{array}{l}\text { Propo } \\
\text { sition }\end{array}$} & \multicolumn{3}{|c|}{ Fischer's Exact } & \multicolumn{2}{c|}{ Graphical modelling } & \multicolumn{3}{c|}{ Items for inclusion } \\
\hline & ADO & PLA & NON & ADO & PLA & NON & ADO & PLA & NON \\
\hline T1 & & $*$ & $*$ & & & & & & \\
\hline T2 & & $* *$ & $* *$ & & & & & + & + \\
\hline O1 & $* * *$ & & $* * *$ & $\leftarrow$ & & $\leftarrow$ & + & & + \\
\hline O5 & $* *$ & & $* * *$ & & & $\leftarrow$ & + & & + \\
\hline O2 & & & & $\leftarrow$ & & & + & & \\
\hline O3 & & & & & & & & & \\
\hline O4 & $* *$ & & $* * *$ & & & & + & & + \\
\hline O6 & $* * *$ & & $* * *$ & & & & + & & + \\
\hline E1 & & $* * *$ & $* * *$ & & & & & + & + \\
\hline E2 & & $* * *$ & $* * *$ & $\leftarrow$ & $\leftarrow$ & $\leftarrow$ & + & + & + \\
\hline E3 & $* * *$ & & $* * *$ & $\leftarrow$ & & $\leftarrow$ & + & & + \\
\hline E5 & & & & & & & & & \\
\hline T3 & $* * *$ & & & & & & + & & \\
\hline T4 & & & & & $\leftarrow$ & & & + & \\
\hline E4 & & $* *$ & & & $\leftarrow$ & $\leftarrow$ & & + & + \\
\hline
\end{tabular}

Legend: $\mathrm{ADO}=$ adopter, $\mathrm{PLA}=$ planner, $\mathrm{NON}=$ non-adopter, ${ }^{*}=\mathrm{p}<=0.050, * *=\mathrm{p}<=$ $0.010, * * *=p<=0.001, \leftarrow=p<=0.05,+=$ item for inclusion in the binary logistic regression analysis.

\subsection{Binary logistic regression analysis}

Binary logistic regression analyses were performed in order to estimate the explanatory power and strength of the adoption motivators summarized in Table 4 for the dependent variables: Adopter, planner, and non-adopter.

The stepwise forward selection method was applied for the logistic regression analysis procedures. The level of inclusion and exclusion was set at the five-percent level. The stepwise method was chosen since it enables examination of the relative strengths of the variables in the model. This 
stepwise approach has another advantage. It is more intuitively appealing since it builds models in a sequential fashion and allows for examination of a collection of models (Hosmer \& Lemeshow, 1989).

\subsubsection{Binary logistic regression analysis for adopters}

Table 5 lists the results of the logistic regression analysis for adopters. Two of the fifteen opinion data items had coefficients that were statistically significant.

Table 3. Logistic regression analysis for adopters

\begin{tabular}{lccccc}
\hline \multicolumn{2}{l}{ Maximum Likelihood Estimates } & \multicolumn{3}{l}{ Odds Ratio Estimates } \\
\hline Parameter & Estimate & $\operatorname{Pr}>$ ChiSq & Point Estimate & 95\% Wald Confidence Limits \\
\hline Intercept & -1.2413 & 0.0004 & & & \\
O6, yes & 0.5958 & 0.0546 & 3.292 & 0.977 & 11.097 \\
E3, yes & 1.1872 & 0.0008 & 10.744 & 2.700 & 42.747 \\
\hline
\end{tabular}

Response profile

\begin{tabular}{ccc}
\hline Ordered value & Adopters & Total frequency \\
\hline 1 & Yes & 19 \\
2 & No & 58 \\
\hline
\end{tabular}

Hosmer and Lemeshow Goodness-of-Fit Test

Chi-Square DF PR > ChiSq

$\begin{array}{lll}4.3804 & 2 & 0.1119\end{array}$

Since the Hosmer and Lemeshow Goodness-of-Fit Test p-value (0.1119) is greater than 5 percent this supports the fit of the model.

\subsubsection{Binary logistic regression analysis for planners}

Table 6 lists the results of the logistic regression analysis for planners. Two of the fifteen opinion data items had coefficients that were statistically significant.

Table 4. Logistic regression analysis for planners

\begin{tabular}{lrrrrr}
\hline \multicolumn{2}{l}{ Maximum Likelihood Estimates } & \multicolumn{3}{l}{ Odds Ratio Estimates } \\
\hline Parameter & Estimate & Pr $>$ ChiSq & Point Estimate & 95\% Wald Confidence Limits \\
\hline Intercept & -1.5351 & 0.0073 & & & \\
E2, yes & 1.1998 & $<.0001$ & 11.019 & 3.492 & 34.764 \\
E4, yes & -1.2237 & 0.0327 & 0.087 & 0.009 & 0.817 \\
\hline
\end{tabular}

Response profile

\begin{tabular}{ccc}
\hline Ordered value & Planners & Total frequency \\
\hline 1 & Yes & 27 \\
2 & No & 50 \\
\hline
\end{tabular}

Hosmer and Lemeshow Goodness-of-Fit Test

Chi-Square DF PR $>$ ChiSq

$\begin{array}{lll}0.1637 & 2 & 0.9214\end{array}$ 
Since the Hosmer and Lemeshow Goodness-of-Fit Test p-value (0.9214) is greater than 5 percent this supports the fit of the model.

\subsubsection{Binary logistic regression analysis for non-adopters}

Table 7 lists the results of the logistic regression analysis for Nonadopters. Three of the fifteen opinion data items had coefficients that were statistically significant.

Table 5. Logistic regression analysis for non-adopters

\begin{tabular}{lccccc}
\hline \multicolumn{2}{l}{ Maximum Likelihood Estimates } & \multicolumn{3}{l}{ Odds Ratio Estimates } \\
\hline Parameter & Estimate & Pr $>$ ChiSq & Point Estimate & 95\% Wald Confidence Limits \\
\hline Intercept & -2.2777 & 0.0011 & & & \\
O6, yes & -1.1409 & 0.0147 & 0.102 & 0.016 & 0.639 \\
E2, yes & -1.4475 & 0.0026 & 0.055 & 0.008 & 0.363 \\
E3, yes & -1.9272 & 0.0015 & 0.021 & 0.002 & 0.229 \\
\hline
\end{tabular}

Response profile

\begin{tabular}{ccc}
\hline Ordered value & Non-adopters & Total frequency \\
\hline 1 & Yes & 27 \\
2 & No & 45 \\
\hline
\end{tabular}

Hosmer and Lemeshow Goodness-of-Fit Test

Chi-Square DF $\quad$ PR $>$ ChiSq

$\begin{array}{lll}1.5645 & 4 & 0.8152\end{array}$

Since the Hosmer and Lemeshow Goodness-of-Fit Test p-value (0.8152) is greater than 5 percent this supports the fit of the model.

Table 6. Overview of the odds ratio estimates for adopters, planners, and non-adopters

\begin{tabular}{llll}
\hline Proposition & Adopter & Planner & $\begin{array}{l}\text { Non- } \\
\text { adopter }\end{array}$ \\
\hline $\begin{array}{l}\text { O6: The notion that companies considering themselves to } \\
\text { be well prepared for EDI are more likely to adopt EDI }\end{array}$ & 3.292 & 0.102 \\
\hline $\begin{array}{l}\text { E2: The prospect of increasing the company's market share } \\
\text { is a motivator for EDI adoption }\end{array}$ & 11.019 & 0.055 \\
\hline $\begin{array}{l}\text { E3: The knowledge that several business partners already } \\
\text { use EDI is a motivator for EDI adoption }\end{array}$ & 10.744 & 0.021 \\
\hline $\begin{array}{l}\text { E4: The fact that EDI has been recommended by others is a } \\
\text { motivator for EDI adoption }\end{array}$ & 0.087 & \\
\hline
\end{tabular}

Propositions related to the technological context were not found to influence the motivation for adoption for any of the responders regardless of level of adoption. One reason could be that the opinion data items were not well-defined. As shown in the Cronbach's coefficient alpha test the construct of the technological context was not well-defined for any of the three adoption levels.

For adopters and non-adopters factors related to the organizational context and environmental context were found to explain motivation for EDI 
adoption or non-adoption. For planners opinion data related to the environmental context were found to explain the motivation for EDI adoption. In the following section a closer look at the significance of each of the explanatory opinion data items in relation to the adoption level is presented.

\section{DISCUSSION OF RESULTS}

\subsection{Factors motivating adoption}

Two factors were found to motivate EDI adoption. The two propositions O6, "The notion that companies considering themselves to be well prepared for EDI are more likely to adopt EDI" and E3, "The knowledge that several business partners already use EDI is a motivator for EDI adoption" could not be rejected.

One could argue that proposition O6, "The notion that companies considering themselves to be well prepared for EDI are more likely to adopt EDI" from a managerial point of view comprises all the organizational context opinion items. When a company states, that it is well prepared for EDI adoption this implies that the remaining organizational context items in some way or other are covered.

Another interpretation of the outcome of the analysis of adopters could find support in the nature of the social system (Rogers, 1995). If the prevailing attitude in the social system is, that EDI adoption is the norm, then companies are likely to perceive themselves to be ready for adoption. The common problem, which according to Rogers, is one of the characteristics of the nature of the social system, is then related to efficiency. The mutual goal therefore is to improve efficiency through EDI adoption thereby creating interorganizational efficiency and network externalities. Next, the importance of organizational readiness could be a result of the influence from change agents' promotional efforts, which through campaigns have informed about the innovation. The importance of proposition $\mathrm{O} 6$ is according to this interpretation influenced by social processes and communicated information about the innovation. If this type of interpretation is used, then the knowledge that several business partners already use EDI (proposition E3) is supporting the notion of a social process attitude towards adoption even more strongly.

Amongst the environmental context opinion data items proposition E3 appears to be the most important statement. The awareness that business partners already use EDI induces the potential adopters to perceive adoption to be the norm. Another interpretation of the importance of proposition E3 
for adopters can be supported by the exponential diffusion curve (Attewell, 1992). Adoption according to this view becomes more and more attractive the more people adopt the innovation. This is especially the case when interorganizational attributes are related to an innovation, where critical mass is important for benefits to accrue from the investment (Markus, 1987).

One aspect, which is important to consider, when interpreting the priorities indicated by the adopters, is that their responses reflect an ex post evaluation. The two propositions, O6 and E3, that were found to be statistical significant in the logistic regression analysis are less concrete and less specific and therefore of a more general nature than the rest of the propositions comprising the organizational context and the environmental context. Instead of specifically replying that the motivation for adoption was for example related to concrete attributes the motivation is expressed in more general terms.

\subsection{Factors motivating companies planning to adopt EDI}

Two factors were found to motivate companies considering adopting EDI. Propositions E2, "The prospect of increasing the company's market share is a motivator for EDI adoption" and E4, "The fact that EDI has been recommended by others is a motivator for EDI adoption" could not be rejected.

For planners the determining factors motivating EDI adoption are solely related to the environmental context. Here it should be noted that planners do not consider recommendations from others to be of any importance. This indicates that recommendations from other businesses and from business associations are of no importance when businesses decide to adopt EDI. This appears to be in contrast to the variables determining adoption defined by Rogers. As mentioned in relation to adopters the variables related to the nature of the social systems and change agents' promotion efforts were used as a suitable framework for understanding why these particular propositions were of relevance for adopters.

One interpretation is that rationality rather than social processes drive the motivation for EDI adoption amongst the responders that indicated that they plan EDI adoption. One reason could be that planners compared to adopters indicated contemporary adoption preferences contrary to the adopters who expressed an ex post evaluation of their motivation for adoption. The planners in contrast to the adopters indicate more concrete motivation priorities. This suggests that the planners independent of recommendations from change agents and norms in the social system consider adoption of EDI to improve the organizations' strategic performance, thereby leading to increased market shares. 


\subsection{Factors causing a non-adopting attitude towards EDI}

Three factors were found to cause a non-adopting attitude towards EDI. Propositions O6, "The notion that companies considering themselves to be well prepared for EDI are more likely to adopt EDI" E2, "The prospect of increasing the company's market share is a motivator for EDI adoption", and E3, "The knowledge that several business partners already use EDI is a motivator for EDI adoption" could not be rejected. ${ }^{2}$

The environmental context seemed to be the dominant explanatory factor for responders remaining as non-adopters. One opinion data item related to the organizational context was however also found to be a significant explanatory factor for non-adopters. Proposition O6 was found to be of major importance for adopters. Non-adopters on the other hand stated that they did not consider organizational readiness to be of any importance with respect to EDI adoption. A similar pattern was found in relation to proposition E3. This opinion data item was of major importance for adopters, whereas it had no relevance for the non-adopters at all. However, there might be some logical explanation for this inconsistency of preferences amongst the two levels of adoption - what makes good sense for adopters and planners, does not appear to make sense for non-adopters. Common for all opinion data items for non-adopters was that they did not agree with any of these statements.

One explanation for the situation, that non-adopters do not find EDI attractive at all, might be found in the attributes of the non-adopting companies included in the analysis sample. The non-adopters were generally small and independent companies. Such companies are believed to have limited power to initiate an EDI partnership and they are most likely allotted the role of an EDI follower. It is generally found that followers do not derive the same benefits of EDI as initiators (Swatman \& Swatman, 1992). Operational and strategic gains from EDI adoption for small companies might therefore be limited. This is also the case in relation to the five innovation attributes defined by Rogers (1995). The relative advantage of EDI for small adopters is limited in relation to the efforts required to set-up an EDI solution with a few business partners.

It was argued that one possible reason for adopters indicating that organizational readiness was a motivator for EDI adoption was to be found in the nature of the social system and the change agents' promotion efforts. ${ }^{2}$ In this respect it is important to remember that the questionnaire items for non-adopters were
all phrased negatively. 
Organizational readiness was according to the responders of no relevance for non-adopters. An interpretation of this outcome is that non-adopters did not consider themselves to be addressees of the EDI campaigns launched by change agents. Pedagogical intervention (Eckhoff, 1983; Henriksen, 2002) might therefore be of limited value for companies that postpone or reject adoption of EDI. Additionally, the norms of the social system, which they perceive themselves to belong to, may not attach any value to EDI.

The two opinion data items concerning the environmental context, which resulted from the logistic regression analysis for non-adopters, were related to a possible increase of the company's market-share due to EDI adoption and the awareness that several business partners were using EDI. Proposition E3 was considered as the mildest form of pressure leading to EDI adoption among the fifteen opinion data items. This external "community" pressure did not influence non-adopters. A rational interpretation could be that nonadopters could not foresee that they would reach a critical mass of business partners using EDI. An interpretation guided by social processes could be that non-adopters simply do not identify themselves with EDI adopters. Therefore, there is no basis for an imitation process. With respect to proposition E2 it could be argued that if the non-adopters had found that EDI adoption in any way would influence their market share in a positive way, then they probably already would have adopted EDI.

To sum up, it looks like the non-adopters think that they can do fine without this innovation. And therefore they do not agree with or show any sign of enthusiasm with respect to any of the defined motivators for EDI adoption.

\section{CONCLUDING REMARKS}

About $16 \%$ of the companies in the Danish steel and machinery industry had adopted EDI by the time of the survey. The national share was in comparison about 15\% (Henriksen, 2002). Given the claimed strategic and operational advantages companies can derive from EDI adoption this low level of adoption is difficult to understand. In the reported survey fifteen propositions related to a mix of operational and strategic benefits of EDI were tested based on data from 247 Danish companies in the steel and machinery industry. The objective of the study was to uncover the patent priorities of the responders. Based on our analysis it was found that organizational and environmental attributes rather than technological attributes determined EDI adoption in this particular sector. Pressure and organizational readiness were found to be the primary motivating factors for EDI adoption and rejection of the innovation. 
One of the lessons learned from the study is that there is a discrepancy in the way an innovation is presented by business associations and the way it is perceived in the business community. The business associations representing the steel and machinery industry communicated the innovation as a means for improving competitive advantage. However, businesses belonging to the categories of planners and non-adopters did not share this viewpoint. Planners were not open to recommendations from others but they did at the same see EDI as a competitive tool namely as a means for increasing their market share. What is remarkable in this survey is that what made adopters accept the innovation was exactly what influenced non-adopters not to adopt. They disagreed with the notion that organizational readiness or pressure would influence their decision to adopt. Similar to planners the opinion data item related to increase of market share was also one of the patent priorities of non-adopters. However, non-adopters did not find that this item would influence their decision to adopt.

It is surprising that the responders do not pay much attention to the technological attributes as promoters or inhibitors of adoption. One reason could be that the awareness campaigns on EDI after all have "de-mystified" the technological dimension of EDI. Another, and perhaps more plausible explanation is that the technological attributes related to an innovation determines the rate of adoption less than IS researchers normally expect.

\section{REFERENCES}

Abrahamson, E. (1996) Management Fashion. The Academy of Management Review 21, 254285.

Andersen, K. V., Juul, N. C., Henriksen, H. Z., Bjorn-Andersen, N., \& Bunker, D. (2000) Business-to-Business E-commerce, Enterprises Facing a Turbulent World. DJØF Publishers, Copenhagen.

Arunachalam, V. (1995) EDI: An Analysis of Adoption, Uses, Benefits and Barriers. Journal of Systems Management 60-64.

Attewell, P. (1992) Technology Diffusion and Organizational Learning: The Case of Business Computing. Organization Science 3, 1-19.

Bergeron, F. \& Raymond, L. (1992) The Advantages of Electronic Data Interchange. DATABASE 23, 19-31.

Chatfield, A.T. \& Bjorn-Andersen, N. (1997) The Impact of IOS-enabled Business Process Change on Business Outcomes: Transformation of the Value Chain of Japan Airlines. Journal of Management Information Systems 14, 13-40.

Chau, P.Y.K. (2001) Inhibitors to EDI Adoption in Small Businesses: An Empirical Investigation. Journal of Electronic Commerce Research 2, 1-19.

Chau, P.Y.K. \& Tam, K.Y. (1997) Factors Affecting the Adoption of Open Systems: An Exploratory Study. MIS Quarterly March, 1-21. 
Choudhury, V., Hartzel, K.S., \& Konsynski, B.R. (1998) Uses and Consequences of Electronic Markets: An Empirical Investigation in the Aircraft Parts Industry. MIS Quarterly December, 471-507.

Clark, T. \& Stoddard, D. B. (1996) Interorganizational Business Process Redesign: Merging Technological and Process Innovation. Journal of Management Information Systems 13, 9-28.

Cooper, R.B. \& Zmud, R.W. (1990) Information Technology Implementation Research: A Technological Diffusion Approach. Management Science 36, 123-139.

Cox, B. \& Ghoneim, S. (1996) Drivers and Barriers to Adopting EDI: A Sector Analysis of UK Industry. European Journal of Information Systems 5, 24-33.

Crum, M., Premkumar, G., \& Ramamurthy, K. (1996) An Assessment of Motor Carrier Adoption, Use, and Satisfaction with EDI. Transportation Journal 35, 44.

Dearing, B. (1990) The Strategic Benefits of EDI. The Journal of Business Strategy January/February., 4-6.

Downs, G.W. \& Mohr, L.B. (1976) Conceptual Issues in the Study of Innovation. Administrative Science Quarterly 21, 700-714.

Eckhoff, T. (1983) Statens styringsmuligheter. Sarlig i ressurs- og miljøspфrsmål. TANUM NORLI, Oslo.

Grover, V. (1993) An Empirically Derived Model for the Adoption of Customer-based Interorganizational Systems. Decision Sciences 24, 603-640.

Harrison, D. A., Mykytyn, P.P., \& Riemenschneider, C.K. (1997) Executive Decisions About Adoption of Information Technology in Small Business: Theory and Empirical Tests. Information Systems Research 8, 171-195.

Hart, P. \& Saunders, C. (1998) Emerging Electronic Partnerships: Antecedents and Dimensions of EDI Use from the Supplier's Perspective. Journal of Management Information Systems 14, 87-111.

Hatcher, L. \& Stepanski, E. (1994) A Step-by-Step Approach to Using the SAS System for Univariate and Multivariate Statistics. SAS Institute Inc., Cary.

Henriksen, H.Z. (2002) Performance, Pressures, and Politics: Motivators for Adoption of Interorganizational Information Systems. Samfundslitteratur. URL: http: //www. cbs. dk/staff/hzh/Dissertation. htm (accessed ultimo October 2003).

Hosmer, D.W. \& Lemeshow, S. (1989) Applied Logistic Regression. John Wiley and Sons, New York.

Iacovou, C.L., Benbasat, I., \& Dexter, A.S. (1995) Electronic Data Interchange and Small Organizations: Adoption and Impact of Technology. MIS Quarterly December., 465-485.

Jelassi, T. \& Figon, O. (1994) Competing through EDI at Brun Passot: Achievements in France. MIS Quarterly 18, 337.

Kurnia, S. \& Johnston, R.B. (2000) The Need of a Processual View of Inter-organizational Systems Adoption. Journal of Strategic Information Systems 9, 295-319.

Kwon, T.H. \& Zmud, R.W. (1987) Unifying the Fragmented Models of Information Systems Implementation. In: Critical Issues in Information Systems Research, R.J. Boland and R. A. Hirschheim (ed), pp. 227-251. John Wiley \& Sons Ltd..

Lai, V.S. \& Guynes, J.L. (1997) An assessment of the influence of organizational characteristics on information technology adoption decision: A discriminative approach. IEEE Transactions on Engineering Management 44, 146-157.

Lee, H. G., Clark, T., \& Tam, K. Y. (1999) Research Report: Can EDI Benefit Adopters? Information Systems Research 10, 186-195.

Markus, L.M. (1987) Toward a "Critical Mass" Theory of Interactive Media. Universal Access, Interdependence and Diffusion. Communication Research 14, 491-511. 
Massetti, B. \& Zmud, R.W. (1996) Measuring the Extent of EDI Usage in Complex Organizations: Strategies and Illustrative Examples. MIS Quarterly September, 331-345.

Masters, J.M., Allenby, G.M., LaLonde, B.J., \& Maltz, A. (1992) On the Adoption of DRP. Journal of Business Logistics 13, 47.

Moore, G.C. \& Benbasat, I. (1991) Development of an Instrument to Measure the Perceptions of Adopting an Information Technology Innovation. Information Systems Research 2, 192-222.

Newell, S., Swan, J., \& Galliers, R. (2000) A Knowledge-focused Perspective on the Diffusion and Adoption of Complex Information Technologies: The BPR Example. Information Systems Journal 10, 239-259.

Nunnally, J.C. (1978) Psycometric Theory. McGraw-Hill, New York.

O'Callaghan, R. \& Turner, J.A. (1995) Electronic Data Interchange - Concepts and Issues. In: EDI in Europe: How it Works in Practice, H. Kcmar, N. Bjorn-Andersen, and R. O'Callaghan (eds), pp. 1-19. John Wiley \& Sons Ltd..

Premkumar, G. \& Ramamurthy, K. (1995) The Role of Interorganizational and Organizational Factors on the Decision Mode for Adoption of Interorganizational Systems. Decision Sciences 26, 303-336.

Premkumar, G., Ramamurthy, K., \& Nilakanta (1994) Implementation of Electronic Data Interchange: An Innovation Diffusion Perspective. Journal of Management Information Systems 11, 157-177.

Raymond, L. \& Bergeron, F. (1996) EDI Success in Small and Medium-Sized Enterprises: A Field Study. Journal of Organizational Computing and Electronic Commerce 6, 161-172.

Rogers, E. M. (1995) Diffusion of Innovations. The Free Press.

Siegel, S. \& Castellan, N. J. (1988) Nonparametric Statistics for the Behavioral Sciences. McGraw Hill, Boston.

Srinivasan, K., Kekre, S., \& Mukhopadhyay, T. (1994) Impact of Electronic Data Interchange Technology on JIT Shipments. Management Science 40, 1291-1304.

Steinfield, C., Kraut, R., \& Plummer, A. (1995) The Impact Of Interorganizational Networks On Buyer-Seller Relationships. Journal of Computer-Mediated Communication 1.

Swatman, P.M.C. \& Swatman, P.A. (1992) EDI System Integration: A Definition and Literature Survey. The Information Society 8, 169-205.

Thong, J.Y.L. (1999) An Integrated Model for Information Systems Adoption in Small Businesses. Journal of Management Information Systems 15, 187-214.

Timmers, P. (2000) Electronic Commerce: Strategies And Models For Business-To-Business Trading. Wiley and Sons, New York.

Tornatzky, L. G. \& Fleischer, M. (1990) The Process of Technological Innovation. Lexington Books.

Truman, G.E. (2000) Integration in Electronic Exchange Environments. Journal of Management Information Systems 17, 209-244.

Tuunainen, V.K. (1998) Opportunities of Effective Integration of EDI for Small Businesses in the Automotive Industry. Information \& Management 34, 361-375.

Zaltman, G., Duncan, R., \& Holbek, J. (1973) Innovations and Organizations. John Wiley \& Sons, New York. 